\title{
SPECULATION AND SURVIVAL IN FINANCIAL MARKETS
}

\section{Eugen Kováč}
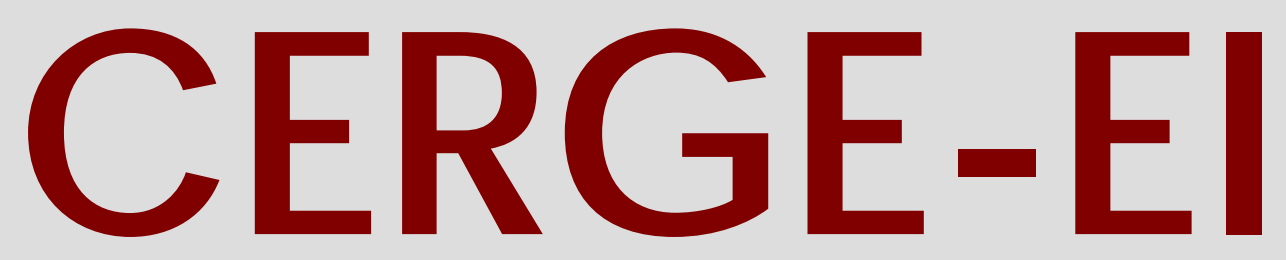

Charles University Centerfor Economic Research and Graduate Education Academy of Sciences of the Czech Republic Ec onomic Institute 


\title{
Working Paper Series $\quad 276$ (ISSN 1211-3298)
}

\section{Speculation and Survival in Financial Markets}

\author{
Eugen Kováč
}

CERGE-EI

Prague, September 2005 
ISBN 80-7343-070-3 (Univerzita Karlova v Praze, CERGE)

ISBN 80-7344-059-8 (Národohospodářský ústav AV ČR, Praha) 


\title{
Speculation and survival in financial markets*
}

\author{
EUGEN KOVÁC̆ ${ }^{\dagger}$ \\ $\left(\mathrm{CERGE}-\mathrm{EI}^{\ddagger}\right)$
}

September 2005

\begin{abstract}
The paper analyzes a finite time economy with a single risky asset which pays a one-shot payoff (dividend). The payoff is random and its distribution is not known à priori. Agents observe public signals (random draws from the same distribution) and update their beliefs about the payoff. They trade in order to reshuffle their portfolios according to new beliefs. Agents may use various updating rules and are considered to be of two types: sophisticated who are aware of their future beliefs and prices, and naive who are not. Drawing on the methodology by Sandroni (2000), it is shown that among sophisticated agents, those with less accurate beliefs are driven out, in the sense that their wealth becomes arbitrarily small when the number of signals is sufficiently large. On the other hand, it is shown that this statement may not hold in economies with naive agents only, where even agents with inaccurate beliefs may survive.
\end{abstract}

*The author would like to thank Ronald W. Anderson, Dirk Engelmann, Jan Kmenta, Tymofiy Mylovanov, Georg Nöldeke, Andreas Ortmann, Frank Riedel, Avner Shaked, Jakub Steiner, Viatcheslav Vinogradov, Petr Zemčík, and Krešimir Žigić for helpful comments. The financial support of the Charles University Grant Agency and hospitality of the University of Bonn are gratefully acknowledged. All errors are mine.

†Address: CERGE-EI, P.O.BOX 882, Politických vězňu 7, 11121 Prague 1, Czech Republic; URL: home.cerge-ei.cz/kovac; e-mail: eugen.kovac@cerge-ei.cz.

$\ddagger$ A joint workplace of the Center for Economic Research and Graduate Education, Charles University, Prague, and the Economics Institute of the Academy of Sciences of the Czech Republic. Address: CERGE-EI, P.O. Box 882, Politických vězňů 7, Prague 1, 111 21, Czech Republic 


\begin{abstract}
Abstrakt
Tento článek analyzuje ekonomiku v konečném čase s jedním riskantním aktivem, které vyplácí jednorázovou dididendu. Výplata je náhodná a její rozdělení není agentům à priori známo. Agenti pozorují veřejné signály (náhodné výběry ze stejného rozdělení) a aktualizují svoje přesvědčení. Obchodují, aby přizpůsobili svá portfolia novým přesvědčením. Agenti mohou používat různá aktualizační pravidla a mohou být dvou typů: sofistikovaní, kteří si jsou vědomi svých budoucích přesvědčení a cen, a naivní, kteří nejsou. Na základě Sandroniho (2000) metodologie, je ukázáno, že mezi sofistikovanými agenty jsou ti $\mathrm{s}$ méně přesnými přesvědčeními vytlačeni $\mathrm{z}$ trhu $\mathrm{v}$ tom smyslu, že jejich bohatství bude libovolně malé, pokud je počet signálů dostatečně velký. Na druhou stranu je ukázáno, že toto tvrzení nemusí platit v ekonomikách s výlučně naivními agenty, kde můžou př̌žít také agenti s méně nepř̀snými přesvědčeními.
\end{abstract}

Keywords: market selection, wealth accumulation, speculation, learning, sophisticated agents, naive agents

JEL classification: D83, D84, G11 


\section{Introduction}

The presence of irrational investors in financial markets has been under debate for decades. Traditional economic theory argues that markets favor rational investors over irrational investors and as a consequence only the rational ones survive (Alchian 1950, Friedman 1953). For instance, inaccurate beliefs, as a possible form of irrationality, cause agents to make wrong investment decisions and hence to lose their wealth in favor of agents with more accurate beliefs. This way, agents with accurate beliefs accumulate all the wealth and drive the ones with inaccurate beliefs out of the market.

This long-standing view (also called market selection hypothesis) has been undermined by empirical and behavioral finance literature. The empirical literature has documented several anomalies not consistent with rational behavior. ${ }^{1}$ Building on these empirical findings, the behavioral finance literature started to analyze theoretically the effects irrational investors have on financial markets. ${ }^{2}$ It argues that the presence of irrational investors with specific cognitive biases could be an explanation for certain anomalies.

On the other hand, there is an emerging literature on market selection, providing rigorous models for the market selection hypothesis. Blume and Easley (1992, 2004) and Sandroni (2000, 2004) consider survival of agents in financial markets in a general equilibrium model with infinitely living agents. In particular, Sandroni (2000) analyzes a model of Lucas trees (Lucas 1978). He considers agents who are self-aware (in the sense that they anticipate their own future behavior) and shows that those with less accurate beliefs are driven out of the market. There are two reasons why markets favor agents with more accurate beliefs. First, agents with less

\footnotetext{
${ }^{1}$ For example, negative correlation of abnormal returns to firm size (Banz 1981), excessive volatility (Shiller 1981), short-term momentum (Jegadeesh and Titman 1993), long-term reversal (De Bondt and Thaler 1985). See, for example, Hirshleifer (2001) for an overview.

${ }^{2}$ See De Long, Shleifer, Summers and Waldmann (1990), Shleifer and Vishny (1997), Daniel, Hirshleifer and Subrahmanyam (1998), Shefrin and Statman (1994), etc.
} 
accurate beliefs make wrong investment decisions on average more often and hence receive on average lower dividends. Second, agents with less accurate beliefs make wrong predictions of future prices and hence make losses from trading. Therefore, in the future they have lower wealth as perceived by the market. In this paper, I separate the two reasons. I am interested whether inaccuracy in predictions of prices (the second reason) is sufficient for determining survival in financial markets. Therefore I introduce a model which abstracts from the fact that agents with less accurate beliefs receive on average lower dividend payoffs. ${ }^{3}$

In particular, I consider a finite time economy with dividends being paid only once (in the last period). The distribution of dividends is not known to agents who use estimates of the distribution in order to determine their investment decisions. Prior the realization of dividends, agents observe public signals about their distribution. After observing a signal, agents update their estimates using various updating rules. Following Sandroni (2000), I consider a very general class of updating rules and processes (which may not be necessarily Bayesian).

As a further step compared to the literature on market selection, the structure of my model also offers an opportunity to analyze behavior of agents who are not self-aware. In addition to differences in updating rules, I consider two types of agents: sophisticated and naive. Sophisticated agents have a certain degree of foresight (perfect or limited) and are able to predict their future behavior and prices for several periods. ${ }^{4}$ On the other hand, naive agents are assumed to have no foresight (i.e., are not self-aware), in the sense that they do not anticipate their own future behavior and prices. This introduces another dimension of irrationality in the model, which has not yet been analyzed in the relation to market selection.

\footnotetext{
${ }^{3}$ The first reason may also also be of interest. It can be analyzed, for instance, in the multiarmed bandits setting; see, for example, Gittins (1979).

${ }^{4}$ Foresight means that the agent knows his own future beliefs and prices contingent on the state (path of signals). It does not mean that the agent knows which signals will indeed occur in the future.
} 
In this paper I am particularly interested in how market selection works among naive agents in comparison to sophisticated agents.

Drawing on the methodology by Sandroni (2000), I show that among sophisticated agents, the ones with inaccurate beliefs are driven out of the market. This means that their wealth becomes arbitrarily small when the number of signals is sufficiently large. Compared to Sandroni (2000), the present model abstracts from the first reason for survival listed above, i.e., that agents with less accurate beliefs receive on average lower dividends. I show that the second reason is sufficient for driving agents with less accurate beliefs out of the market. This is a further step in understanding the determinants of survival in financial markets.

More specifically, in my model agents have lower wealth only because they bet on wrong price changes on average more often and lose because they have different (less accurate) beliefs than others. Thus their wealth (as perceived by the market via equilibrium prices) becomes eventually lower with increasing number of signals. If the number of signals is sufficiently large, the wealth ratio between an agent with less accurate and more accurate beliefs will be close to zero, which means that the former is driven out of the market. Moreover, the setup with a single dividend is closer to the behavioral finance literature. Hence this model suggests that some results, in behavioral finance, e.g., short-term momentum and long-term reversal by Daniel et al. (1998), may be caused only by short-run effects and may not be persistent in the long-run (see Section 5 for a more extensive discussion).

On the other hand, selection among naive agents does not work this way. As opposed to the case of sophisticated agents, even agents with inaccurate beliefs may be able to survive when all agents are naive. This is shown in the special case where all agents hold constant beliefs. In this case naive agents stop trading, since the optimal portfolio under their beliefs does not change. Therefore, all of them are able to survive. This result is in sharp contrast with the case of sophisticated 
agents. If their beliefs are close to a constant, agents holding different beliefs keep trading and the ones with more accurate beliefs drive those with inaccurate belief out.

The reminder of this paper is organized as follows. In Section 2, I describe the economy. In Section 3, I introduce and solve agents' maximization problems and describes the equilibrium. Section 4 contains the main results on survival in financial markets. Section 5 concludes.

\section{The model}

\subsection{Description of the economy}

I consider a finite discrete time economy with finitely many agents (denoted $1,2, \ldots, n$ ) and a single consumption good. The consumption good is available in the last period (period $T+1$ ) as a dividend from a risky asset which is available in unit supply. In addition, there is a risk-less asset available in zero supply which simply represents borrowing and lending among agents. The dividend paid by the risky asset may have value either $d_{1}$ or $d_{0}$ units of the consumption good, where $d_{1}>d_{0}$. Value $d_{1}$ represents a high dividend whereas value $d_{0}$ represents a low dividend. The underlying uncertainty is about the distribution of the last period's dividends which is known to agents except for a parameter. I assume that $d=d_{1}$ with probability $\pi$ and $d=d_{0}$ with probability $1-\pi$. Formally, $d=d_{S}$ where $S$ is a Bernoulli distributed random variable. The exact value of $\pi$ is not known to agents who use its estimates to compute their expected utilities.

In period 0 , each agent $i \in I=\{1,2, \ldots, n\}$ is endowed with a share of the risky asset. In periods $1,2, \ldots, T$, agents observe public signals about the distribution of last periods' returns. The signals are random draws from the same distribution as $S$, i.e., they are realizations of random variables $S_{1}, S_{2}, \ldots, S_{T}$ and are assumed 
to be independent from dividends. This i.i.d. property is common knowledge. Realization $S_{t}=1$ represents a high signal, whereas realization $S_{t}=0$ represents a low signal. Obviously, the signals entail no information about the realization of dividends and their only purpose is to update the estimates of $\pi$.

Formally, I assume that $S_{1}, S_{2}, \ldots, S_{T}$, and $S$ are independent and identically distributed random variables, ${ }^{5}$ i.e., these are Bernoulli random variables with the same distribution as $S$ (with $\pi$ as probability of a high signal). Based on the signals agents adjust their holdings of the risky asset and risk-less asset in order to maximize their expected utility from consumption in the last period. Note that this approach is different from the classical market microstructure literature, where the exact distribution of dividends and signals is known and signals are correlated with dividends. Hence realizations of signals entail information about the realization of dividends. ${ }^{6}$ Here, the signals entail no information about the realization of dividends and serve the purpose of updating the estimates (or beliefs) about the unknown parameter. The assumption of identical distribution of dividends and signals relates inaccuracy in predictions of dividends to inaccuracy in predictions of signals. For example, if signals are interpreted as information about the state of the company, it means that company with higher expected return will have on average high signals more often. Moreover, agents who predict that the company is in a good state (i.e., yields a high dividend), predict high signals to occur more often.

\subsection{Updating, sophistication, and naivety}

Denote $\pi_{0}^{i}$ agent $i$ 's initial estimate of $\pi$, and $\pi_{t}^{i}\left(s_{1}, \ldots, s_{t}\right)$ his estimate of $\pi$ in period $t$ after observing signals $S_{1}=s_{1}, \ldots, S_{t}=s_{t}$. Instead of specifying concrete

\footnotetext{
${ }^{5}$ Sometimes, when convenient, I denote $S_{T+1}=S$.

${ }^{6}$ See, for example, Grossman and Stiglitz (1980) and Hirshleifer, Subrahmanyam and Titman (1994).
} 
updating rules where $\pi_{t}^{i}$ is a recursive function of previous beliefs and realizations (as, for example, for Bayesian updating), I simply assign to each path of signals an estimate $\pi_{t}^{i}\left(s_{1}, \ldots, s_{t}\right) \cdot{ }^{7}$ This definition allows for a broad class of updating rules. Following Sandroni (2000), I assume that the beliefs are given exogenously, i.e., the beliefs are not affected by the information revealed by prices. ${ }^{8}$

As a special case, rational agents have well defined prior beliefs about $\pi$ which are subsequently updated according to Bayes rule. On the other hand, there may be agents who are exposed to various cognitive errors which cause deviations from Bayesian updating. ${ }^{9}$ These may be underweighting of base rate information, overconfidence, biased self-attribution, etc. ${ }^{10}$ As an example consider an agent who believes that $\pi$ is either $\tilde{\pi}$ or $1-\tilde{\pi}$ (where $\tilde{\pi}>\frac{1}{2}$ ). The agent can be called overconfident if he believes that $\pi=\tilde{\pi}$ when the number of high signals is higher than the number of low signals, and that $\pi=1-\tilde{\pi}$ in the opposite case.

Remark 1 . Note that with prior beliefs about $\pi$ given by a density function $f_{0}^{i}(\pi)$ the expected value (estimate) of $\pi$ is $\pi_{0}^{i}=\int_{0}^{1} \pi f_{0}^{i}(\pi) \mathrm{d} \pi$. Obviously, if some random variable $X$ attains values $x_{1}, x_{0}$ with probabilities $\pi, 1-\pi$ respectively, then with prior beliefs $f_{0}^{i}(\pi)$, the expected value of $X$ is $\mathrm{E}_{0}^{i} X=\pi_{0}^{i} x_{1}+\left(1-\pi_{0}^{i}\right) x_{0}$.

In addition to information processing errors, I distinguish between two types of agents based on their foresight abilities. These are sophisticated and naive agents. The concepts of sophistication and naivety are not unified in the literature, but mainly they are related to time consistency. For example, Eliaz and Spiegler (2004) consider naive agents who cannot perfectly forecast their future tastes. In this paper, naive agents are assumed to have no foresight and hence they are not able to predict their beliefs and prices. They behave as if there would be no further

\footnotetext{
${ }^{7}$ In other words, $\pi_{t}^{i}$ is a random variable measurable at time $t$.

${ }^{8}$ See Mailath and Sandroni (2003) for an alternative approach.

${ }^{9}$ See Epstein and Sandroni (2003) for a general framework for non-Bayesian updating.

${ }^{10}$ See Kahneman, Slovic and Tversky (1982) for a general treatment, Hirshleifer (2001) for an overview of applications in financial markets.
} 
signals.

On the other hand sophisticated agents are assumed to have a certain degree of foresight: either perfect or limited (but not zero). This means that they are aware of their future beliefs and future prices (conditional on signals). As a special case, agents with perfect foresight are aware of all their future beliefs and prices, whereas agents with limited foresight are aware of future beliefs and prices only for a limited number of periods. As will be shown later (Proposition 1), agents who are aware of future prices for at least one period behave identically. Hence, it is appropriate to call them all, somewhat simplistically, sophisticated. I will discuss the difference between sophisticated and naive agents in more detail later in Subsections 3.2 and 3.3 when describing their maximization problems.

\subsection{Financial markets}

In period 0 each agent $i \in I$ is endowed with $\alpha_{0}^{i}>0$ shares of the risky asset. Denote $\left(\alpha_{t}^{i}, \beta_{t}^{i}\right)$ agent $i$ 's portfolio at the beginning of period $t$. The variable $\alpha_{t}^{i}$ represents agent $i$ 's holding of the risky asset at the beginning of period $t$. Similarly, the variable $\beta_{t}^{i}$ represents the holding of the risk-less asset. I assume that there is no debt present in period 0, i.e., $\beta_{0}^{i}=0$ for each agent $i \in I$. After observing a signal, agents' estimates (beliefs) of $\pi$ may change and hence their expectation of dividends in period $T+1$ may change. Therefore, agents may be willing to reshuffle their portfolios and trade with each other. Moreover, agents may trade for speculative reasons. This means that having different beliefs about the future distribution of prices, agents try to exploit this difference in order to obtain the best portfolio when the dividends are realized.

For simplicity I assume that the risk-free interest rate is zero. Let $q_{t}$ be the share price at time $t$ (after observing the signal) expressed in terms of the consumption good, i.e., $q_{t}$ represents the exchange rate between the consumption good and the 
risky asset. ${ }^{11}$ Holding a portfolio $\left(\alpha_{t}^{i}, \beta_{t}^{i}\right)$ at the beginning of period $t$, agent $i$ 's wealth after observing the signal is

$$
w_{t}^{i}=\alpha_{t}^{i} q_{t}+\beta_{t}^{i}
$$

This wealth is to be redistributed between the risky and risk-less asset. The choice must satisfy the budget constraint

$$
\alpha_{t+1}^{i} q_{t}+\beta_{t+1}^{i}=w_{t}^{i}, \quad \text { for } i \in I .
$$

The markets clear if the aggregate demand equals the aggregate supply, i.e.,

$$
\begin{aligned}
& \sum_{i \in I} \alpha_{t+1}^{i}=1, \\
& \sum_{i \in I} \beta_{t+1}^{i}=0 .
\end{aligned}
$$

As a simple consequence of the three above conditions, the total wealth in the economy is

$$
\sum_{i \in I} w_{t}^{i}=q_{t}
$$

This simply represents the fact that there are no other sources of wealth than the risky asset.

\section{Agents' problems and equilibrium}

\subsection{Last period's maximization}

For $t=0,1,2, \ldots, T$ denote by $\mathrm{E}_{t}^{i}$ the expectation operator associated with agent $i$ 's beliefs (estimate $\pi_{t}^{i}$ ) in period $t$ (conditional on available information $S_{1}, \ldots, S_{t}$ ).

\footnotetext{
${ }^{11}$ The exchange rate for risk-less asset is 1 . Further, when convenient, I will denote $q_{T+1}=d$.
} 
In addition denote $\mathrm{E}$ the true expectation operator associated with the true probabilities. In order to formulate the agents' maximization problems I will proceed backwards and start with period $T$. The maximization problem in period $T$ is the same for sophisticated and naive agents.

I assume that agent $i$ has logarithmic utility and maximizes his expected utility

$$
\mathrm{E}_{T}^{i} \log w_{T+1}
$$

where $w_{T+1}=\alpha_{T+1}^{i} d+\beta_{T+1}^{i}$. The assumption of logarithmic utility is commonly used in the financial markets literature. ${ }^{12}$ The main reason for doing so is that its maximization coincides with maximization of wealth accumulation. It also allows for a simple structure of agents' investment decisions and makes the model tractable. ${ }^{13}$

After substituting the budget constraint into the expected utility, I obtain

$$
\begin{aligned}
& \mathrm{E}_{T}^{i} \log w_{T+1}=\mathrm{E}_{T}^{i} \log \left(\alpha_{T+1}^{i} d+\beta_{T+1}^{i}\right)=\mathrm{E}_{T}^{i} \log \left[\alpha_{T+1}^{i}\left(d-q_{T}\right)+w_{T}^{i}\right]= \\
& =\pi_{T}^{i} \log \left[\alpha_{T+1}^{i}\left(d_{1}-q_{T}\right)+w_{T}^{i}\right]+\left(1-\pi_{T}^{i}\right) \log \left[\alpha_{T+1}^{i}\left(d_{0}-q_{T}\right)+w_{T}^{i}\right]
\end{aligned}
$$

Knowing the price $q_{T}$ in period $T$, the above expression is to be maximized with respect to $\alpha_{T+1}^{i}$. It is easy to check that its second derivative is non-negative. ${ }^{14}$ Moreover, in order to have a maximum, it is necessary that $\left(d_{1}-q_{T}\right)\left(d_{0}-q_{T}\right)<0$, or equivalently $d_{1}>q_{T}>d_{0}$. Otherwise, by the usual no-arbitrage argument, there is no maximum and the agent wants to take an infinite (positive or negative) position. Technically, in such a case the expected utility is strictly increasing or

\footnotetext{
${ }^{12}$ See, for example, Blume and Easley (2002), Mailath and Sandroni (2003), and Beker (2004).

${ }^{13}$ Although the specific form of the results (separation result in Proposition 1) relies on the logarithmic form of the utility function, the main results of this paper should still hold for a utility function which is "close" to the logarithmic function (for example, constant relative risk aversion utility with risk aversion parameter close to 1). It is not clear, whether they carry over to a more general class of utility functions.

${ }^{14}$ It can be zero only when $q_{T}=d_{1}, \pi=1$, or $q_{T}=d_{0}, \pi=0$.
} 
strictly decreasing in $\alpha_{T}^{i}$ and hence agent $i$ is willing to take an infinite position.

If the above condition is satisfied, the first order conditions for agent $i$ 's maximization problem yield the solution where

$$
\frac{\alpha_{T+1}^{i}}{w_{T}^{i}}=-\frac{1}{\left(d_{1}-q_{T}\right)\left(d_{0}-q_{T}\right)}\left(\mathrm{E}_{T}^{i} d-q_{T}\right)
$$

and $\beta_{T+1}^{i}=w_{T}^{i}-q_{T} \alpha_{T+1}^{i}$. Observe that the share $\alpha_{T+1}^{i}$ agent $i$ demands is positive (i.e., the agent takes a long position) if his expected value of dividends is higher than the current price, and negative (i.e., the agent takes a short position) if his expected value of dividends is lower than the current price. Using the fact that $w_{T+1}^{i}=\alpha_{T+1}^{i}\left(d-q_{T}\right)+w_{T}^{i}$, the above demand yields the following wealth in the last period:

$$
w_{T+1}^{i}= \begin{cases}w_{T}^{i} \frac{d_{1}-d_{0}}{q_{T}-d_{0}} \pi_{T}^{i}, & \text { if } d=d_{1}, \\ w_{T}^{i} \frac{d_{1}-d_{0}}{d_{1}-q_{T}}\left(1-\pi_{T}^{i}\right), & \text { if } d=d_{0} .\end{cases}
$$

This shows that the wealth in period $T+1$ when $d=d_{1}$ is increasing in $\pi_{T}^{i}$ and wealth in period $T+1$ when $d=d_{0}$ is decreasing in $\pi_{T}^{i}$. Therefore, agent $i$ 's wealth is higher in a particular realization of dividends, when he expects the realization with a higher probability.

\subsection{Sophisticated agents}

As defined earlier, sophisticated agents are aware of how signals affect their future beliefs (estimates) and of the future distribution of prices for at least one period. Hence, in period $T-1$ a sophisticated agent $i$ anticipates the equilibrium in period $T$ and maximizes

$$
\mathrm{E}_{T-1}^{i} \mathrm{E}_{T}^{i} \log w_{T+1}^{i}
$$

In other words, the agent maximizes his expected utility from period $T+1$ knowing that in period $T$ his beliefs will be $\pi_{T}^{i}$, price of the risky asset will be $q_{T}$ (with 
some abuse of notation), and hence that he will decide according to (6). After substituting for $w_{T+1}^{i}$ from (7), the previous formula becomes

$$
\mathrm{E}_{T-1}^{i} \log w_{T}^{i}+\mathrm{E}_{T-1}^{i} \log \pi_{T}^{i}+\left[\pi_{T-1}^{i} \log \frac{d_{1}-d_{0}}{q_{T}-d_{0}}+\left(1-\pi_{T-1}^{i}\right) \log \frac{d_{1}-d_{0}}{d_{1}-q_{T}}\right]
$$

Obviously the last two terms are not affected by the decision in period $T-1$. Hence for a sophisticated agent, the maximization of $\mathrm{E}_{T-1}^{i} \mathrm{E}_{T}^{i} \log w_{T+1}^{i}$ is equivalent to maximization of $\mathrm{E}_{T-1}^{i} \log w_{T}^{i}$. The solution of this problem is analogous to (6).

The above means that, in order to maximize his last period's utility, in period $T-1$ the agent maximizes his utility from the wealth in period $T$. In other words, he maximizes the expected logarithm of his budget available for investment in the next period. Hence, the investment decisions in these periods can be evaluated separately which means that only next period variables are relevant for current investment decisions. Note that the underlying assumption which allows for this "separation" result is the logarithmic form of the utility function.

By the same procedure for periods $T-2, \ldots, 2,1,0$, the following proposition immediately follows. ${ }^{15}$

Proposition 1. For any sophisticated agent $i \in I$, the decision problem in period $t \in\{0,1, \ldots, T\}$ is equivalent to maximization of

$$
\mathrm{E}_{t}^{i} \log w_{t+1}^{i}=\pi_{t}^{i} \log \left(\alpha_{t+1}^{i} q_{t+1}(1)+\beta_{t+1}^{i}\right)+\left(1-\pi_{t}^{i}\right) \log \left(\alpha_{t+1}^{i} q_{t+1}(0)+\beta_{t+1}^{i}\right),
$$

subject to the budget constraint (2). Its solution is then given by

$$
\frac{\alpha_{t+1}^{i}}{w_{t}^{i}}=-\frac{1}{\left(q_{t+1}(1)-q_{t}\right)\left(q_{t+1}(0)-q_{t}\right)}\left(\mathrm{E}_{t}^{i} q_{t+1}-q_{t}\right)
$$

\footnotetext{
${ }^{15}$ As above, I will denote $q_{t+1}\left(s_{t}\right)$ the price of the risky asset conditional on signal $S_{t}=s_{t}$ in period $t$. A proper notation would be $q_{t+1}\left(s_{1}, \ldots, s_{t-1}, s_{t}\right)$ and $q_{t}\left(s_{1}, \ldots, s_{t-1}\right)$ instead of $q_{t+1}\left(s_{t}\right)$ and $q_{t}$, respectively.
} 
and $\beta_{t+1}^{i}=w_{t}^{i}-\alpha_{t+1}^{i} q_{t}$, under the condition $\left(q_{t+1}(1)-q_{t}\right)\left(q_{t+1}(0)-q_{t}\right)<0$.

Obviously, if $q_{t+1}(1)>q_{t}>q_{t+1}(0)$, i.e., the price rises when a high signal is observed and the price drops when a low signal is observed, the demanded share $\alpha_{t+1}^{i}$ increases with the expected future price $\mathrm{E}_{t}^{i} q_{t+1}$. This means that the more optimistic agent $i$ is, the higher share of the risky asset he demands.

Formula (8) can be rewritten in the following form:

$$
\alpha_{t+1}^{i}=-w_{t}^{i}\left[\frac{\pi_{t}^{i}}{q_{t+1}(0)-q_{t}}+\frac{1-\pi_{t}^{i}}{q_{t+1}(1)-q_{t}}\right]
$$

It indicates that smaller price changes cause the agent to take more extreme positions. This is a consequence of risk aversion, since with smaller price changes, the agent is exposed to less risk. On the other hand, large price changes are associated with higher risk and hence the agent prefers positions which are small (in absolute value).

Moreover, (9) shows that the demanded share $\alpha_{t+1}^{i}$ is increasing in $q_{t+1}(1)$ and in $q_{t+1}(0)$. In other words, agents demand more of the risky asset if some of the future prices are higher. The effect of $q_{t}$ on the demanded share $\alpha_{t+1}^{i}$ is not so obvious. After substituting (1) into the equality (9), taking derivative with respect to $q_{t}$ and using that $\alpha_{t}^{i} q_{t}+\beta_{t}^{i}=w_{t}^{i}>0$, I obtain $\partial \alpha_{t+1}^{i} / \partial q_{t}=-\pi_{t}^{i}\left(\alpha_{t}^{i} q_{t+1}(0)+\beta_{t}^{i}\right) /\left(q_{t+1}(0)-\right.$ $\left.q_{t}\right)^{2}-\left(1-\pi_{t}^{i}\right)\left(\alpha_{t}^{i} q_{t+1}(1)+\beta_{t}^{i}\right) /\left(q_{t+1}(1)-q_{t}\right)^{2}$. This is obviously negative whenever $\alpha_{t}^{i} q_{t+1}(0)+\beta_{t}^{i}>0$ and $\alpha_{t}^{i} q_{t+1}(1)+\beta_{t}^{i}>0$.

The above proposition generalizes the separation result for earlier periods. Its counterpart in infinite time horizon models is the fact that in a rational expectations equilibrium with logarithmic utility, the agents' beliefs over future wealth distributions are irrelevant; see, for example, Mailath and Sandroni (2003). The 
solution from Proposition 1 yields the wealth growth rate ${ }^{16}$

$$
\frac{w_{t+1}^{i}}{w_{t}^{i}}= \begin{cases}\frac{q_{t+1}(1)-q_{t+1}(0)}{q_{t}-q_{t+1}(0)} \pi_{t}^{i}, & \text { if } S_{t+1}=1, \\ \frac{q_{t+1}(1)-q_{t+1}(0)}{q_{t+1}(1)-q_{t}}\left(1-\pi_{t}^{i}\right), & \text { if } S_{t+1}=0 .\end{cases}
$$

This formula is a generalization of (7) for the last period. Similarly, as for the last period, agent's wealth is higher in a particular realization of dividends, when he expects the realization with a higher probability. More precisely, the wealth growth rate is decomposed in two positive factors. The first factor represents the price change and is constant across individuals. The second factor represents individual beliefs. Hence, the relative wealth growth rate is determined only by a ratio of individual beliefs. Comparing the wealth growth rate across agents formally (consider two agents $i$ and $j$ ), I obtain

$$
\frac{w_{t+1}^{i} / w_{t}^{i}}{w_{t+1}^{j} / w_{t}^{j}}= \begin{cases}\frac{\pi_{t}^{i}}{\pi_{t}^{j}}, & \text { if } S_{t+1}=1 \\ \frac{1-\pi_{t}^{i}}{1-\pi_{t}^{j}}, & \text { if } S_{t+1}=0\end{cases}
$$

If $\pi_{t}^{i}>\pi_{t}^{j}$, agent $i$ has a higher wealth growth rate when a high signal is observed (i.e., $S_{t+1}=1$ ), but a lower wealth growth rate when a low signal is observed (i.e., $\left.S_{t+1}=0\right)$. This already indicates the main intuition behind survival of agents who have more accurate belief — agents who have more accurate beliefs predict correctly the price change on average more often. Hence, they achieve on average a higher wealth growth rate. Therefore, on average they accumulate more wealth and survive.

Remark 2. Above I have described and solved the agents' problems recursively. For sophisticated agents with perfect foresight (or with foresight for at least $T$ periods),

\footnotetext{
${ }^{16}$ Note the well known fact that maximization of logarithmic utility is equivalent to maximization of the wealth growth rate.
} 
the problems can be formulated also directly as maximization of

$$
\mathrm{E}_{0}^{i} \mathrm{E}_{1}^{i} \ldots \mathrm{E}_{T}^{i} \log \left[w_{0}^{i}+\sum_{t=0}^{T} \alpha_{t+1}^{i}\left(q_{t+1}-q_{t}\right)\right]
$$

subject to the sequence of budget constraints (2).

In an economy where all agents are sophisticated, the equilibrium is determined by their demands given by (8) and market clearing conditions (3). Using the market clearing condition for period $t+1$, I obtain

$$
\sum_{i \in I} w_{t}^{i}\left(\mathrm{E}_{t}^{i} q_{t+1}-q_{t}\right)=-\left(q_{t+1}(1)-q_{t}\right)\left(q_{t+1}(0)-q_{t}\right)
$$

Substitution of $w_{t}^{i}=\alpha_{t}^{i} q_{t}+\beta_{t}^{i}$ and the market clearing conditions (3), (4) for period $t$ yield

$$
q_{t}=\frac{q_{t+1}(1) q_{t+1}(0)+\sum_{i \in I} \beta_{t}^{i} \mathrm{E}_{t}^{i} q_{t+1}}{q_{t+1}(1)+q_{t+1}(0)-\sum_{i \in I} \alpha_{t}^{i} \mathrm{E}_{t}^{i} q_{t+1}}
$$

Obviously, using again the market clearing conditions (3), (4), the equality (12) can be written equivalently as

$$
\frac{1}{q_{t}}=\frac{\sum_{i \in I} \alpha_{t}^{i} \mathrm{E}_{t}^{i} \frac{1}{q_{t+1}}}{1-\sum_{i \in I} \beta_{t}^{i} \mathrm{E}_{t}^{i} \frac{1}{q_{t+1}}}
$$

As a special case, I can evaluate the price when all agents' estimates in period $t$ are the same (equal to $\pi_{t}^{i}$ ). In this case, the market clearing conditions imply

$$
\frac{1}{q_{t}}=\mathrm{E}_{t}^{i} \frac{1}{q_{t+1}}=\frac{\pi_{t}^{i}}{q_{t+1}(1)}+\frac{1-\pi_{t}^{i}}{q_{t+1}(0)},
$$

which means that the current price is a weighted harmonic average of future prices. Remark 3. If we consider the risky asset as the numeraire and denote $r_{t}=1 / q_{t}$ the price of the risk-less asset (i.e., 1 unit of risk-less asset is worth $r_{t}$ units of risky asset), the above equality can be interpreted as a martingale property for $r_{t}$. 
Remark 4. Note also that in equilibrium the investors' wealth is positive. Hence, (10) implies that $\left(q_{t+1}(1)-q_{t}\right)\left(q_{t+1}(0)-q_{t}\right)<0$, i.e., $q_{t}$ lies between $q_{t+1}(0)$ and $q_{t+1}(1)$.

\subsection{Naive agents}

In contrast to sophisticated agents, naive agents have no foresight. This means that such agents are not aware of their future beliefs and future prices. As a result, naive agents behave as if there would be no further signals in the future, i.e., as if the dividend is realized in the next period. Knowing the current price $q_{t}$, such agent $i$ maximizes in each period $t \leq T$ the following perceived expected utility

$$
\mathrm{E}_{t}^{i} \log w_{T+1}=\mathrm{E}_{t}^{i} \log \left[\alpha_{t+1}^{i}\left(d-q_{t}\right)+w_{t}^{i}\right]
$$

Its maximization, subject to the budget constraint (2) yields, similarly as for sophisticated agents, the following solution

$$
\frac{\alpha_{t+1}^{i}}{w_{t}^{i}}=-\frac{1}{\left(d_{1}-q_{t}\right)\left(d_{0}-q_{t}\right)}\left(\mathrm{E}_{t}^{i} d-q_{t}\right)
$$

under the condition $d_{1}>q_{t}>d_{0}$. Note that this is the same as for sophisticated agents where $q_{t+1}(1)=d_{1}$ and $q_{t+1}(0)=d_{0}$. Similarly as for sophisticated agents, here the demanded share increases with $\mathrm{E}_{t}^{i} d$.

In an economy where all agents are naive, the equilibrium is determined by their demands given by (14) and market clearing conditions (3). These yield

$$
\sum_{i \in I} w_{t}^{i}\left(\mathrm{E}_{t}^{i} d-q_{t}\right)=-\left(d_{1}-q_{t}\right)\left(d_{0}-q_{t}\right) .
$$


Analogously as for sophisticated agents, the equilibrium price in period $t$ is

$$
q_{t}=\frac{d_{1} d_{0}+\sum_{i \in I} \beta_{t}^{i} \mathrm{E}_{t}^{i} d}{d_{1}+d_{0}-\sum_{i \in I} \alpha_{t}^{i} \mathrm{E}_{t}^{i} d} .
$$

Note also that similarly as for sophisticated agents, if all agents have the same estimates in period $t$, the current price is a harmonic average of final period's dividends.

\section{Survival in the long-run}

\subsection{Generalized framework}

In this section I analyze survival in financial markets. I apply the methodology of Sandroni (2000) to the economy described in the previous section when the number of signals $T$ is large. Towards this end, I introduce a more general formulation of the agents' beliefs which will be more convenient in the further discussion. Consider an infinite sequence $\bar{S}=\left(S_{1}, S_{2}, \ldots\right)$ of independent identically distributed (i.i.d.) Bernoulli random variables with $\pi$ being the probability of realization 1 . These random variables reperesent the signals. Let $\mathcal{P}$ denote the probability measure on $\{1,0\}^{\infty}$, that induces such distributions. ${ }^{17}$ This framework covers also an economy with $T$ signals in the sense introduced in Section 2. It is sufficient to assume that the signals can continue to infinity, but since the payoffs are realized in period $T+1$, the signals observed after this period are irrelevant. Let agent $i$ 's beliefs (estimates) be represented by a probability measure $\mathcal{P}^{i}$ on $\{1,0\}^{\infty}$. Hence, each agent has well defined beliefs for an infinite sequence of random variables.

Following Sandroni (2000), I introduce a new notation. In general, consider an arbitrary probability measure $\mathcal{Q}$ on $\{1,0\}^{\infty}$, and an arbitrary sequence $\bar{s}=$

\footnotetext{
${ }^{17}$ By $\{1,0\}^{\infty}$ I mean the set of all sequences of ones and zeros. For simplicity I omit the definition of the underlying $\sigma$-algebra. See Sandroni (2000) for details.
} 
$\left(s_{1}, s_{2}, \ldots\right) \in\{1,0\}^{\infty}$. For any $t=0,1,2, \ldots$ denote $d \mathcal{Q}_{t}(\bar{s})$ the $\mathcal{Q}$-measure of the set $\left\{\bar{S} \in\{1,0\}^{\infty} \mid S_{1}=s_{1}, \ldots, S_{t}=s_{t}\right\}$, i.e., the set of all sequences for which first $t$ elements coincide with the first $t$ elements of $\bar{s}$ (for convenience set $\left.d \mathcal{Q}_{-1}=1\right)$. Further denote $\mathcal{Q}_{t}(\bar{s})=d \mathcal{Q}_{t}(\bar{s}) / d \mathcal{Q}_{t-1}(\bar{s})$. This represents the conditional $\mathcal{Q}$-probability (measure) that $S_{t}=s_{t}$ conditional on $S_{1}=s_{1}, \ldots, S_{t-1}=s_{t-1}$. Moreover, let $\mathrm{E}^{\mathcal{Q}}$ denote the expectation operator associated with probability measure $\mathcal{Q}$.

The relation between the above definitions and the definitions from Section 2 are expressed by the following equalities

$$
\begin{aligned}
\mathcal{P}_{t+1}\left(s_{1}, \ldots, s_{t}, 1, s_{t+2} \ldots\right) & =\pi \\
\mathcal{P}_{t+1}\left(s_{1}, \ldots, s_{t}, 0, s_{t+2} \ldots\right) & =1-\pi \\
d \mathcal{P}_{t}^{i}(\bar{s}) & =\pi^{\sum_{\tau=1}^{t} s_{t}}(1-\pi)^{1-\sum_{\tau=1}^{t} s_{t}},
\end{aligned}
$$

and for agent $i$ the equalities:

$$
\begin{aligned}
\mathcal{P}_{t+1}^{i}\left(s_{1}, \ldots, s_{t}, 1, s_{t+2} \ldots\right) & =\pi_{t}^{i}\left(s_{1}, \ldots, s_{t}\right) \\
\mathcal{P}_{t+1}^{i}\left(s_{1}, \ldots, s_{t}, 0, s_{t+2} \ldots\right) & =1-\pi_{t}^{i}\left(s_{1}, \ldots, s_{t}\right) \\
d \mathcal{P}_{t}^{i}(\bar{s}) & =\prod_{\tau=1}^{t}\left[s_{\tau} \pi_{\tau-1}^{i}+\left(1-s_{\tau}\right)\left(1-\pi_{\tau-1}^{i}\right)\right],
\end{aligned}
$$

where $\bar{s}=\left(s_{1}, \ldots, s_{t}, \ldots\right)$. In the last formula, the expression in brackets is equal to $\pi_{\tau-1}^{i}$ whenever $s_{\tau}=1$ and to $1-\pi_{\tau-1}^{i}$ whenever $s_{\tau}=0$. Hence, $d \mathcal{P}_{t}^{i}(\bar{s})$ represents the probability with which agent $i$ believes that path $s_{1}, \ldots, s_{t}$ will occur and $\mathcal{P}_{t}^{i}(\bar{s})$ is the conditional probability that the signal in period $t$ will be $s_{t}$ conditional on observing signals $S_{1}=s_{1}, \ldots, S_{t-1}=s_{t-1}$ in previous periods. Note that the definition implicitly assumes that $\mathcal{P}_{t+1}^{i}(\bar{s})$ does not depend on $s_{t+2}, s_{t+3}, \ldots$, which means that beliefs are conditioned only on history (and not on future). The 
equalities for probability measure $\mathcal{P}$ are special cases which can be obtained by substituting $\pi_{t}^{i}=\pi$.

Henceforth, I will assume that $\mathcal{P}_{t}^{i}$ is uniformly bounded away from zero and one, for any agent $i \in I$ and any $t=1,2, \ldots, \mathcal{P}$-a.s. (i.e., with $\mathcal{P}$-probability one). This means that with certainty agents $i$ 's beliefs do not become close to certainty. ${ }^{18}$ Note that this property holds for Bayesian beliefs whose support does not contain 0 and 1 (note that the support is by definition a closed set).

\subsection{Market selection}

Let $\bar{s}=\left(s_{1}, s_{2}, \ldots\right) \in\{1,0\}^{\infty}$ be a path of signals and $d_{s}$ (where $s \in\{1,0\}$ ) be the dividends. I will call the pair $(s, \bar{s})$ a realization. For any $T=1,2, \ldots$, I will call $T$-economy, the economy with $T$ signals and $(s, \bar{s})$-equilibrium of the $T$-economy, the equilibrium of the $T$-economy where $S_{1}=s_{1}, \ldots, S_{T}=s_{T}$, and $S=s$. Further, I will refer to $w_{T+1}^{i}$ as agent $i$ 's final wealth in a $T$-economy (i.e., after the dividends are realized).

Consider an agent $i$ and the process of his wealth accumulation for realization $(s, \bar{s})$. I say that agent $i$ survives on realization $(s, \bar{s})$, if agent $i$ 's final equilibrium wealth in $(s, \bar{s})$-equilibrium of every $T$-economy is bounded away from zero. ${ }^{19} \mathrm{On}$ the other hand, I say that agent $i$ is driven out on realization $(s, \bar{s})$, if for any $\varepsilon>0$ agent $i$ 's final $(s, \bar{s})$-equilibrium wealth of the $T$-economy is smaller than $\varepsilon$, if sufficiently many signals are observed. ${ }^{20}$

\footnotetext{
${ }^{18}$ Formally, for any path $\bar{s}$, there exists a constant $\varepsilon>0$ such that $\varepsilon<\mathcal{P}_{t}^{i}(\bar{s})<1-\varepsilon$, for $t=1,2, \ldots, \mathcal{P}$-a.s.

${ }^{19}$ Formally, this means that there exists $\varepsilon>0$ such that $w_{T+1}^{i}>\varepsilon$ in $(s, \bar{s})$-equilibrium of $T$-economy, for any $T=1,2, \ldots$.

${ }^{20}$ Formally, this means that for any $\varepsilon>0$ there exists $T_{0}$ such that $w_{T+1}^{i}<\varepsilon$ in $(s, \bar{s})$-equilibrium of $T$-economy whenever $T>T_{0}$.
} 


\subsection{Selection among sophisticated agents}

In this subsection, I analyze selection among sophisticated agents. In general (with one exception in Proposition 2) I do not require all agents to be sophisticated. Naive agents may also be present in the economy. However, the results below describe only selection among sophisticated agents in such an economy.

For a sophisticated agent $i$, equality (10) can be rewritten as follows:

$$
\frac{w_{t+1}^{i}}{w_{t}^{i}}=(-1)^{1+s_{t+1}} \frac{q_{t+1}(1)-q_{t+1}(0)}{q_{t+1}\left(s_{t+1}\right)-q_{t}}\left[s_{t+1} \pi_{t}^{i}+\left(1-s_{t+1}\right)\left(1-\pi_{t}^{i}\right)\right] .
$$

Hence on any realization $(s, \bar{s})$, where $\bar{s}=\left(s_{1}, s_{2}, \ldots\right)$, the following equality, which is a generalization of (11), holds:

$$
\frac{w_{t}^{i} / w_{0}^{i}}{w_{t}^{j} / w_{0}^{j}}=\frac{d \mathcal{P}_{t}^{i}(\bar{s})}{d \mathcal{P}_{t}^{j}(\bar{s})}
$$

for any $t=1,2, \ldots, T+1$ and any two agents $i, j \in I$. This is the crucial equality which drives all the results. It indicates that agents' wealth growth rates on a certain realization are proportional to their subjective probabilities with which agents believe the realization occurs. Hence agents, who compared to others believe that some path is more likely, have a higher wealth on that path. Hence in the limit, they survive on this path. A precise statement is formulated in the proposition below (the statement is based on Sandroni's (2000) Lemma 2).

Proposition 2. For any sophisticated agent $i \in I$ and realization $(s, \bar{s})$, where $\bar{s} \in\{1,0\}^{\infty}$ and $s \in\{1,0\}$, the following statements hold:

1. If there exists a sophisticated agent $j$ such that $d \mathcal{P}_{t}^{i}(\bar{s}) / d \mathcal{P}_{t}^{j}(\bar{s}) \rightarrow 0$ as $t \rightarrow \infty$, then agent $i$ is driven out on realization $(s, \bar{s})$.

2. If all agents are sophisticated and for any agent $j$ there exists $\delta>0$ such that $d \mathcal{P}_{t}^{i}(\bar{s}) / d \mathcal{P}_{t}^{j}(\bar{s})>\delta$ for every $t=1,2, \ldots$, then agent $i$ survives on realization 
$(s, \bar{s})$.

Proof. See Appendix.

Remark 5. Consider $T_{1}>T_{2}$, a realization $(s, \bar{s})$, and two agents $i, j \in I$. Although their wealths $w_{t}^{i}$ and $w_{t}^{j}$ may be different in a $(s, \bar{s})$-equilibrium of $T_{2}$-economy and first $T_{2}$ periods in a $(s, \bar{s})$-equilibrium of $T_{1}$-economy, the ratio $\left(w_{T+1}^{i} / w_{0}^{i}\right) /\left(w_{T+1}^{j} / w_{0}^{j}\right)$ is the same since it depends only on agents' beliefs on the realization $(s, \bar{s})$. Analogically the ratios $w_{t}^{i} / w_{t}^{j}$ are the same in periods $1,2, \ldots, T_{2}$.

Proposition 2 is intuitive and gives a criterion for determining survival of agents for a particular realization, i.e., ex-post. On the other hand, from ex-ante perspective, agents who predict paths correctly with a higher probability, have a higher probability of survival. A non-rigorous argument can be stated as follows. According to the law of large numbers, on a particular path, there will be frequency $\pi$ of high signals increases and frequency $1-\pi$ of low signals. For illustration consider an agent with constant beliefs $\pi^{i}$. In order to survive on such paths, his beliefs should maximize $\left(\pi^{i}\right)^{\pi}\left(1-\pi^{i}\right)^{1-\pi}$, or equivalently $\pi \log \pi^{i}+(1-\pi) \log \left(1-\pi^{i}\right)$, across all agents. This expression attains maximum for $\pi^{i}=\pi$ meaning that the agent with correct beliefs will survive. Moreover, the above expression indicates that entropy is the appropriate measure for determining the survival.

Following Blume and Easley (1992) and Sandroni (2000), for agent $i \in I$ define the entropy of his beliefs on path $\bar{s}$ in period $t$ as

$$
\begin{aligned}
\mathcal{E}_{t}\left(\mathcal{P}^{i}\right) & =\mathrm{E}^{\mathcal{P}}\left(\log \frac{\mathcal{P}_{t}^{i}}{\mathcal{P}_{t}} \mid s_{1}, \ldots, s_{t-1}\right)= \\
=\mathcal{E}\left(\pi_{t}^{i}\right) & =\pi \log \frac{\pi_{t}^{i}}{\pi}+(1-\pi) \log \frac{1-\pi_{t}^{i}}{1-\pi} .
\end{aligned}
$$

The entropy is always non-positive and is equal to zero only when the agent has rational expectations (i.e., $\pi_{t}^{i}=\pi$ ). The following proposition formalizes the above 
argument and shows that entropy is indeed the appropriate measure for determining which agent is driven out.

Proposition 3. Let $i, j \in I$ be two sophisticated agents. Then $\mathcal{P}$-a.s. the following statement holds: If there is some $\eta>0$ such that $\mathcal{E}_{t}\left(\mathcal{P}^{i}\right)+\eta \leq \mathcal{E}_{t}\left(\mathcal{P}^{j}\right)$ on path $\bar{s}$, then agent $i$ is driven out on realization $(s, \bar{s})$.

Proof. See Appendix.

Corollary 1. Let $i, j \in I$ be two sophisticated agents. Then $\mathcal{P}$-a.s. the following statement holds: If their beliefs $\pi_{t}^{i}$ and $\pi_{t}^{j}$ converge on path $\bar{s}$ to $\bar{\pi}^{i}$ and $\bar{\pi}^{j}$, respectively, where $\mathcal{E}\left(\bar{\pi}^{i}\right)<\mathcal{E}\left(\bar{\pi}^{j}\right)$, then agent $i$ is driven out on realization $(s, \bar{s})$.

The Corollary is a direct consequence of Proposition 3. According to the assumptions there exists some $\eta>0$ such that $\mathcal{E}\left(\pi_{t}^{i}\right)+\eta<\mathcal{E}\left(\pi_{t}^{j}\right)$ when $t$ is large enough. Therefore, agent $i$ is driven out on realization $(s, \bar{s})$.

Note that in Proposition 3, the realization of dividend is not important for survival. The investment decisions after observing signals are relevant. An investor with less accurate beliefs (with a lower entropy) will over time accumulate less wealth in any equilibrium of the $T$-economy when $T$ is large enough. Hence, in period $T$ he has a lower budget (as perceived by the market) available to make the investment decision. Since his beliefs for the next signal (if there is some) are less accurate too, so are his beliefs about the final distribution of dividends. Hence, his investment decision for period $T+1$ will be worse too.

\subsection{Selection when all agents are naive: An example}

In the previous subsection it was shown that sophisticated agents with less accurate beliefs are driven out by those with more accurate beliefs. Now I will show that this statement may not hold among naive agents. In particular, I consider an 
equilibrium in an economy with naive agents only. The following proposition shows that even agents with inaccurate beliefs may survive.

Proposition 4. Let $t \in\{0,1, \ldots, T\}$ be a time period. If all agents are naive and $\pi_{t+1}^{i}=\pi_{t}^{i}$ for each agent $i$, then $q_{t+1}=q_{t}$ and $w_{t+1}^{i}=w_{t}^{i}, \alpha_{t+2}^{i}=\alpha_{t+1}^{i}$, and $\beta_{t+2}^{i}=\beta_{t+1}^{i}$, for any agent $i$.

Proof. See Appendix.

The above proposition claims that in a steady-state situation, i.e., when the agents' beliefs do not change, the price does not change too. As a consequence, agents stop trading and their holdings of the risky and risk-less asset, and hence their wealths, remain constant. This way, all agents are able to survive, regardless of their beliefs. Therefore, even an agent with completely incorrect belief may survive, as formulated in the following corollary.

Corollary 2. If all agents are naive and their beliefs do not change on path $\bar{s}$ starting from some period $t$, then all agents survive on path $\bar{s}$.

This result is in sharp contrast with the case of sophisticated agents. Note that it is not possible that the price remains constant in an equilibrium of the economy where all agents are sophisticated. According to Corollary 1, for beliefs which converge (sufficiently quickly) to a fixed constant, the agent for whom the constant has a lower entropy is driven out. The main difference between those two situations (i.e., naive agents with constant beliefs and sophisticated agents with almost constant beliefs) is that naive agents stop trading when their beliefs do not change, whereas, as (11) shows, sophisticated agents anticipating possible future price changes (even if small) still try to exploit the difference in belief. This way all naive agents are able to survive among naive agents, whereas among sophisticated agents those with less accurate beliefs are driven out. 
Example 1. Let $d_{1}=2, d_{0}=1$ and let the true probability of high dividend be $\pi=0.1$. Consider an economy with two naive agents who hold constant beliefs: one of them has correct beliefs (rational expectations), i.e., $\pi_{t}^{1}=0.1$, whereas the other has completely incorrect beliefs, say $\pi_{t}^{1}=0.9$ (with entropy -1.7578 ). Corollary 2 claims that both agents will survive and by Proposition 4 their wealths remain constant.

In addition, assume that both agents hold the same share $\frac{1}{2}$ of the risky asset in period 0 . In this case the agents' wealth will be equal to their wealths in period 1 (they may be reshuffling their portfolios in period 0 ). Then, it is easy to compute that the equilibrium price is $q_{t}=\frac{4}{3} \approx 1.3333$, and that agents hold portfolios $\left(\alpha_{t}^{1}, \beta_{t}^{1}\right)=(-0.7,1.6)$, and $\left(\alpha_{t}^{2}, \beta_{t}^{2}\right)=(1.7,-1.6)$. Agent 1 correctly anticipates that the dividend will be most probably low and takes a short position in the risky asset. In periods $0,1, \ldots, T$, the wealth of each agent is $w_{t}^{1}=w_{t}^{2}=2 / 3$. In period $T+1$, when $d=d_{1}=2$, their wealths will be $w_{T+1}^{1}=0.2$ and $w_{T+1}^{2}=1.8$. On the other hand, when $d=d_{0}$ the wealths will be $w_{T+1}^{1}=0.9$ and $w_{T+1}^{2}=0.1$. Note that under the true probabilities, agent 1's expected utility is -0.2558 , whereas agent 2 's expected utility is -2.0136 .

\section{Conclusion}

This paper contributes to the literature on market selection. Unlike most of the recent literature, I consider an economy where a dividend is realized only once, in a given period of time. The exact value of the dividend is not known to agents who receive signals about its distribution and update their beliefs. These beliefs are reflected in the equilibrium prices. Agents may be exposed to various errors in information processing. Based on their foresight abilities, I consider two types of agents: sophisticated, who are aware of their information processing mechanism (which may be incorrect due to cognitive errors), and naive, who are not aware of 
that.

The results for sophisticated agents conform to the existing literature. It is shown that agents with less accurate beliefs are driven out of the market. However, current literature considers mainly infinite horizons with agents receiving dividends in every period. In such models, agents with inaccurate beliefs do not survive for two reasons. First, they receive systematically lower dividends. Second, their portfolios are less appropriate for future investment decisions, i.e., have a lower market value. In my model, the first reason is not present and hence agents with less accurate beliefs do not survive only since they bet on average more often on wrong price changes and hence the market value of their portfolios is lower.

On the other hand, these arguments do not hold in economies with naive agents only. In a special case with constant beliefs I show that even agents with inaccurate beliefs may survive. The main reason for this is that naive agents with constant beliefs (which may still be different across agents) stop trading in equilibrium, since they hold the optimal portfolios according to their own beliefs. However, this argument does not hold for sophisticated agents who always try to exploit the difference among the beliefs.

The setup of the model is also close to the behavioral finance literature. My results indicate that some anomalies supported by behavioral finance based on inaccurate beliefs are present only in the short-run when investors with inaccurate beliefs still have a high wealth. In the long-run, as they are driven out of the market, the anomalies may be eliminated. This argument may apply, for example, to the theory of overreaction and underreaction by Daniel et al. (1998). Much like in my model, the authors consider a single asset which pays dividends only in the last period. The dividend is normally distributed with mean zero and some variance. Informed agents know the value of the variance, whereas overconfident agents underestimate it (believe their information is more precise). Agents receive 
signals about the value of the asset. Based on these assumptions, Daniel et al. (1998) show that the asset price exhibits short-term momentum (underreaction) and long-term reversal (overreaction). Although some assumptions in this paper are different from the ones by Daniel, Hirshleifer and Subrahmanyam, the setup is rather similar. Therefore, my results suggest that their arguments may be valid only in the short-run when overconfident agents hold a substantial portion of wealth. However, in the long-run their wealth and hence their effect on asset prices may decline.

Although the work on these issues is not easy, in order to improve our understanding of market selection and of phenomenons observed in financial markets, my model could be in the future extended in several directions:

- It would be interesting to find out how the selection works between a sophisticated and a naive agent. This is in general a rather difficult task, but I hope that at least results with agents holding the same beliefs could be obtained.

- In this paper, I assume that all agents have logarithmic utility. It would be relevant to analyze a model with a more general class of utility functions. As indicated in Subsection 3.1, the results will remain when the utility function is "close" to the logarithmic one. However, it is not clear, how the results translate to a more general class of utility functions.

\section{References}

Alchian, Armen A., "Uncertainty, Evolution and Economic Theory," The Journal of Political Economy, 1950, 58, 211-221.

Banz, Rolf W., "The Relationship between Return and Market Value of Common Stocks," Journal of Financial Economics, 1981, 9 (1), 3-18. 
Beker, Pablo F., "Are Inefficient Enterpreneurs Driven out of the Market?," Journal of Economic Theory, 2004, 114, 329-244.

Blume, Lawrence and David Easley, "Evolution and Market Behavior," Journal of Economic Theory, 1992, 58, 9-40.

and __ , "Optimality and Natural Selection in Markets," Journal of Economic Theory, 2002, 10\%, 95-135.

and ___ , "If You are so Smart, Why aren't You Rich? Belief Selection in Complete and Incomplete Markets," Mimeo, Cornell University, 2004.

Chung, Kai Lai, A Course in Probability Theory, London: Academic Press, 1974.

Daniel, Kent D., David Hirshleifer, and Avanidhar Subrahmanyam, "Investor Psychology and Security Market Under- and Overreactions," The Journal of Finance, 1998, 53 (6), 1839-1885.

De Bondt, Werner F.M. and Richard Thaler, "Does the Stock Market Overreact?," The Journal of Finance, 1985, 40 (3), 793-805.

De Long, J. Bradford, Andrei Shleifer, Lawrence H. Summers, and Robert J. Waldmann, "Noise Trader Risk in Financial Markets," The Journal of Political Economy, 1990, 98 (4), 703-738.

Eliaz, Kfir and Ran Spiegler, "Contracting with Diversely Naive Agents," Mimeo, 2004.

Epstein, Larry G. and Alvaro Sandroni, "Non-Bayesian Updating: A Theoretical Framework," Mimeo, University of Rochester, 2003.

Friedman, Milton, Essays in Positive Economics, Chicago: University of Chicago Press, 1953.

Gittins, John C, "Bandit processes and dynamic allocation indices," Journal of the Royal Statistical Society, Ser. B,, 1979, 41, 148-164. 
Grossman, Sanford J. and Joseph E. Stiglitz, "On the Impossibility of Informally Efficient Markets," The American Economic Review, 1980, 70 (3), $393-408$.

Hirshleifer, David, "Investor Psychology and Asset Pricing," The Journal of Finance, 2001, 56 (4), 1533-1597.

Avanidhar Subrahmanyam, and Sheridan Titman, "Security Analysis and Trading Patterns when Some Investors Receive Information Before Others," The Journal of Finance, 1994, 49 (5), 1665-1698.

Jegadeesh, Narasimhan and Sheridan Titman, "Returns to Buying Winners and Selling Losers: Implication for Stock Market Efficiency," The Journal of Finance, 1993, 48 (1), 65-91.

Kahneman, Daniel, Paul Slovic, and Amos Tversky, Judgment Under Uncertainty: Heuristics and Biases, Cambridge: Cambridge University Press, 1982.

Lucas, Robert, "Asset Prices in an Exchange Economy," Econometrica, 1978, 46, $1492-1445$.

Mailath, George J. and Alvaro Sandroni, "Market Selection and Asymmetric Information," Review of Economic Studies, 2003, 70, 343-368.

Sandroni, Alvaro, "Do Markets Favor Agents able to Make Accurate Predictions?," Econometrica, 2000, 68 (6), 1303-1341. , "Efficient Markets and Bayes' Rule," Mimeo, J.L. Kellogg School of Management, Northwestern University, 2004.

Shefrin, Hersh and Meir Statman, "Behavioral Capital Asset Pricing Theory," Journal of Financial and Quantitative Analysis, 1994, 29 (3), 323-349. 
Shiller, Robert J., "Do Stock Prices Move Too Much to be Justified by Subsequent Changes in Dividends?," The American Economic Review, 1981, 71 (3), 421-436.

Shleifer, Andrei and Robert W. Vishny, "The Limits of Arbitrage," The Journal of Finance, 1997, 52 (1), 35-55.

\section{A Appendix: Proofs}

Proof of Proposition 2. According to (16), for any $\varepsilon>0$ there exists $T_{1}$ such that

$$
\left(w_{T+1}^{i} / w_{0}^{i}\right) /\left(w_{T+1}^{j} / w_{0}^{j}\right)<\varepsilon
$$

in $(s, \bar{s})$-equilibrium of the $T$-economy for any $T>T_{1}$. By $(5), \sum_{k \in I} w_{T+1}^{k} \in\left\{d_{1}, d_{0}\right\}$ in any equilibrium of the $T$-economy. Moreover, $w_{0}^{j} / w_{0}^{i}=\alpha_{0}^{j} / \alpha_{0}^{i}$, since $\beta_{0}^{i}=\beta_{0}^{j}=0$. Hence, $w_{T+1}^{j}$ is uniformly bounded and for any $\varepsilon>0$ there exists $T_{0}$ such that $w_{T+1}^{i}<\varepsilon$ in $(s, \bar{s})$-equilibrium of the $T$-economy for any $T>T_{0}$. This means that agent $i$ is driven out on realization $(s, \bar{s})$.

On the other hand, assume that there exists some $\xi>0$ (let $\xi<1$ in addition) such that $d \mathcal{P}_{t}^{i}(\bar{s}) / d \mathcal{P}_{t}^{j}(\bar{s})>\xi$ for all agents $j \in I$, in every period $t=1,2, \ldots$ In this case, $\left(w_{T+1}^{i} / w_{0}^{i}\right) /\left(w_{T+1}^{j} / w_{0}^{j}\right)>\xi$ for all agents $j \in I$ (and even for agent $i$ ). If agent $i$ is driven out on realization $(s, \bar{s})$, then for any $\varepsilon>0$ there is $T_{2}$ such that $w_{T+1}^{i}<\varepsilon$ in $(s, \bar{s})$-equilibrium for all $T>T_{2}$. Hence,

$$
w_{T+1}^{j}<w_{0}^{j} / w_{0}^{i} \cdot \varepsilon / \xi=\alpha_{0}^{j} / \alpha_{0}^{i} \cdot \varepsilon / \xi
$$

which, by (5), means that

$$
\sum_{j \in I} w_{T+1}^{j}<1 / \alpha_{0}^{i} \cdot \varepsilon / \xi
$$

However, $\sum_{j \in I} w_{T+1}^{j} \in\left\{d_{1}, d_{0}\right\}$, which is a contradiction.

Proof of Proposition 3. The proof follows the proof of Lemma 2 in Sandroni (2004). 
Define random variable $z_{t}=\log \left(\mathcal{P}_{t-1}^{i} / \mathcal{P}_{t-1}^{j}\right)-\mathrm{E}^{\mathcal{P}} \log \left(\mathcal{P}_{t-1}^{i} / \mathcal{P}_{t-1}^{j}\right)$. Obviously, $\mathrm{E}^{\mathcal{P}}\left(z_{t} \mid\right.$ $\left.s_{1}, \ldots, s_{t-1}\right)=0$, for any sequence of signals $\bar{s}=\left(s_{1}, s_{2}, \ldots\right) \in\{1,0\}^{\infty}$ and time $t=$ $1,2, \ldots$ By the law of iterated expectations, the random variables $z_{1}, z_{2}, \ldots$ are pairwise uncorrelated. Furthermore, by assumption, $\log \left(\mathcal{P}_{t-1}^{i} / \mathcal{P}_{t-1}^{j}\right)$ is uniformly bounded. Using the law of large numbers for uncorrelated random variables, ${ }^{21}$ I obtain $\lim _{t \rightarrow \infty} \frac{1}{t} \sum_{k=1}^{t} z_{k} \rightarrow$ $0, \mathcal{P}$-a.s. Moreover, by assumption $\mathrm{E}^{\mathcal{P}} \log \left(\mathcal{P}_{t-1}^{i} / \mathcal{P}_{t-1}^{j}\right) \leq-\eta$. Hence,

$$
\limsup _{t \rightarrow \infty} \frac{1}{t} \log \left(d \mathcal{P}_{t}^{i} / d \mathcal{P}_{t}^{j}\right) \leq-\eta, \quad \mathcal{P} \text {-a.s. }
$$

Therefore, $\lim _{t \rightarrow \infty} \log \left(d \mathcal{P}_{t}^{i} / d \mathcal{P}_{t}^{j}\right)=-\infty, \mathcal{P}$-a.s. and $\lim _{t \rightarrow \infty} d \mathcal{P}_{t}^{i} / d \mathcal{P}_{t}^{j}=0, \mathcal{P}$-a.s. According to Proposition 2, agent $i$ is driven out $\mathcal{P}$-a.s.

Proof of Proposition 4. In order for $q_{t+1}$ to be well defined, by (15) it is necessary that $d_{1}+d_{0} \neq A_{t+1}$. When I denote $A_{t}=\sum_{i \in I} \alpha_{t}^{i} \mathrm{E}_{t}^{i} d$ and $B_{t}=\sum_{i \in I} \beta_{t}^{i} \mathrm{E}_{t}^{i} d$, equality (15) can be rewritten as

$$
A_{t} q_{t}+B_{t}=-d_{1} d_{0}+q_{t}\left(d_{1}+d_{0}\right) .
$$

Subtracting these equalities for period $t+1$ and $t$, I obtain

$$
\left(A_{t+1} q_{t+1}+B_{t+1}\right)-\left(A_{t} q_{t}+B_{t}\right)=\left(q_{t+1}-q_{t}\right)\left(d_{1}+d_{0}\right) .
$$

Further,

$$
\begin{gathered}
A_{t} q_{t}+B_{t}=\sum_{i \in I}\left(\alpha_{t}^{i} q_{t}+\beta_{t}^{i}\right) \mathrm{E}_{t}^{i} d=\sum_{i \in I} w_{t}^{i} \mathrm{E}_{t}^{i} d= \\
=\sum_{i \in I} w_{t}^{i} \mathrm{E}_{t+1}^{i} d=\sum_{i \in I}\left(\alpha_{t+1}^{i} q_{t}+\beta_{t+1}^{i}\right) \mathrm{E}_{t+1}^{i} d=A_{t+1} q_{t}+B_{t+1},
\end{gathered}
$$

which yields

$$
A_{t+1}\left(q_{t+1}-q_{t}\right)=\left(q_{t+1}-q_{t}\right)\left(d_{1}+d_{0}\right) .
$$

Since $d_{1}+d_{0} \neq A_{t+1}$, this means that $q_{t+1}=q_{t}$.

Using the budget constraint I obtain $w_{t}^{i}=\alpha_{t}^{i} q_{t}+\beta_{t}^{i}=\alpha_{t+1}^{i} q_{t}+\beta_{t+1}^{i}=\alpha_{t+1}^{i} q_{t+1}+$

\footnotetext{
${ }^{21}$ See, for example, Chung (1974, Theorem 5.1.2).
} 
$\beta_{t+1}^{i}=w_{t+1}^{i}$. Moreover, the equalities $\pi_{t+1}^{i}=\pi_{t}^{i}, q_{t+1}=q_{t}$, and (14) imply that $\alpha_{t+2}^{i} / w_{t+1}^{i}=\alpha_{t+1}^{i} / w_{t}^{i}$. Hence, $\alpha_{t+2}^{i}=\alpha_{t+1}^{i}$ and $\beta_{t+2}^{i}=\beta_{t+1}^{i}$. This completes the proof. 
Individual researchers, as well as the on-line and printed versions of the CERGE-EI Working Papers (including their dissemination) were supported from the following institutional grants:

- Center of Advanced Political Economy Research [Centrum pro pokročilá politicko-ekonomická studia], No. LC542, (2005-2009),

- Economic Aspects of EU and EMU Entry [Ekonomické aspekty vstupu do Evropské unie a Evropské měnové unie], No. AVOZ70850503, (2005-2010);

- Economic Impact of European Integration on the Czech Republic [Ekonomické dopady evropské integrace na ČR], No. MSM0021620846, (2005-2011);

Specific research support and/or other grants the researchers/publications benefited from are acknowledged at the beginning of the Paper.

(c) Eugen Kováč, 2005

All rights reserved. No part of this publication may be reproduced, stored in a retrieval system or transmitted in any form or by any means, electronic, mechanical or photocopying, recording, or otherwise without the prior permission of the publisher.

Published by

Charles University in Prague, Center for Economic Research and Graduate Education (CERGE) and

Economics Institute (EI), Academy of Sciences of the Czech Republic

CERGE-EI, Politických vězñů 7, 11121 Prague 1, tel.: +420 224005 153, Czech Republic.

Printed by CERGE-EI, Prague

Subscription: CERGE-EI homepage: http://www.cerge-ei.cz

Editors: Directors of CERGE and EI

Managing editors: Deputy Directors for Research of CERGE and EI

ISSN 1211-3298

ISBN 80-7343-070-3 (Univerzita Karlova v Praze, CERGE)

ISBN 80-7344-059-8 (Národohospodářský ústav AV ČR, Praha) 
CERGE-EI

P.O.BOX 882

Politických vězňů 7

11121 Praha 1

Czech Republic http://www.cerge-ei.cz 